\title{
Rice Husk Derived Activated Carbon/Polyaniline Composites As Active Materials For Supercapacitors
}

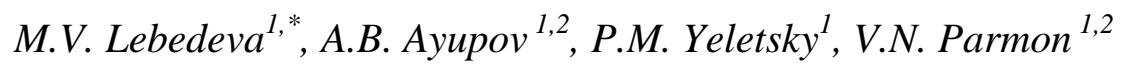 \\ ${ }^{1}$ Boreskov Institute of Catalysis SB RAS, 630090 Novosibirsk, Lavrentieva Av., 5, Russia \\ ${ }^{2}$ Novosibirsk State University, 630090 г. Novosibirsk, Pirogova str., 2, Russia \\ *E-mail: lebedeva@catalysis.ru
}

doi: $10.20964 / 2018.04 .34$

Received: 20 October 2017 / Accepted: 30 January 2018 / Published: 6 March 2018

Composite materials (CM) "carbon/polyaniline" were synthesized using porous activated carbon (AC) produced from carbonized rice husk, which has specific surface area $2265 \mathrm{~m}^{2} \mathrm{~g}^{-1}$ measured by direct BET method. The series of the CM was synthesized by oxidative aniline polymerization method in the presence of the AC in acidic medium; polyaniline (PAni) content was varied from 18 to 60 wt. \%. Electrochemical and properties of the $\mathrm{CM}$ were investigated by cyclic voltammetry, galvanostatic charge/discharge and stability tests. Results indicate that properties of the composites are governed by ratio of the components: a form of cyclic voltammogram curves and location of specific ox-red polyaniline peaks strongly depend on the PAni amount. Gravimetric capacitance grows with polymer content in the material and reaches maxima $465 \mathrm{~F} \cdot \mathrm{g}^{-1}$ in $1 \mathrm{M} \mathrm{H}_{2} \mathrm{SO}_{4}$ at discharge current density $0.2 \mathrm{~A} \cdot \mathrm{g}^{-1}$ for the sample with polyaniline content $60 \mathrm{wt} \%$. However, durability tests show that the most stable is the sample with the lowest $(18 \mathrm{wt} . \%)$ polyaniline amount.

Keywords: Activated carbon, Composite materials, Polyaniline, Rice Husk, Synergetic effect.

\section{FULL TEXT}

(C) 2018 The Authors. Published by ESG (www.electrochemsci.org). This article is an open access article distributed under the terms and conditions of the Creative Commons Attribution license (http://creativecommons.org/licenses/by/4.0/). 